\title{
Method development and validation of simultaneous determination of seventeen metals in water by ICP/MS
}

\author{
Fuad Al-Rimawi ${ }^{(1)}$, Khalid Kanan ${ }^{(2)}$, Mutaz Qutob ${ }^{(3)}$
}

Faculty of Science and Technology, Al-Quds University, P.O. Box 20002, East Jerusalem, Palestinian

Authority, Tel. +972 (0)2 2860791

e-mail: falrimawi@science.alquds.edu.

Faculty of Science and Technology, Al-Quds University, P.O. Box 20002, East Jerusalem, Palestinian

Authority, Tel. +972 (0)2 2794191

e-mail:kanan@admin.alquds.edu

Department of Earth and Environmental studies, Faculty of Science and Technology, Al-Quds University, East Jerusalem, Palestinian Authority, Tel. +972 (0)2 2794191

e-mail: qutob@planet.edu

\begin{abstract}
A simple, precise, accurate, and sensitive method is developed and validated for simultaneous determination of seventeen metals ( $\mathrm{Li}, \mathrm{Sr}, \mathrm{Ba}, \mathrm{TI}, \mathrm{Pb}, \mathrm{Bi}, \mathrm{Al}, \mathrm{K}, \mathrm{Cr}, \mathrm{Mn}, \mathrm{Co}, \mathrm{Ni}, \mathrm{Cu}, \mathrm{Zn}, \mathrm{Mo}, \mathrm{Ag}$, and $\mathrm{Cd}$ ) in water by ICP-MS. The optimum conditions of the ICP-MS are as follows: nebulizer gas (argon) flow rate: $0.9 \mathrm{~L} / \mathrm{min}$, auxiliary gas (argon) flow $0.3 \mathrm{~L} / \mathrm{min}$, plasma (argon) gas flow: $15 \mathrm{~L} / \mathrm{min}$, reaction gas flow (helium) $4 \mathrm{~mL} / \mathrm{min}$. This method is validated according to the requirements for new methods, which include linearity and range, accuracy, precision, selectivity, limit of detection (LOD), and limit of quntitation (LOQ). The current method demonstrates good linearity over the range of 1-1000 ppb with $r^{2}$ greater than 0.999 for the seventeen metals. The recovery of the metals from water samples ranges from 97.5 to $101.7 \%$. The method is selective where minimal interferences between the metals is observed $\left(\mathrm{CeO} / \mathrm{Ce}=1 \%\right.$, and $\left.\mathrm{Ce}^{+2} / \mathrm{Ce}^{+1}=1 \%\right)$, and with good resolution ( $0.8 \mathrm{amu}$ at $10 \%$ height). The method is also precise where the RSD of the responses (cps) of replicates of the metals at three concentration levels is less than 1\%. Low LOD and LOQ of metals using this method enable the detection and quantitation of these metals at low concentrations. Real water samples from West Bank in Palestine (groundwater) were analyzed for their trace metals content using this method.
\end{abstract}

\section{Indexing terms/Keywords}

heavy metals; validation; ICP/MS; linearity; recovery; precision; LOD; LOQ.

\section{Academic Discipline And Sub-Disciplines}

Analytical chemistry

\section{SUBJECT CLASSIFICATION}

Chemistry Subject Classification; Library of Congress Classification

\section{TYPE (METHOD/APPROACH)}

Lab Analysis

\section{Council for Innovative Research}

Peer Review Research Publishing System

Journal: Journal of Advances in Chemistry

Vol.4, No.3
editor@cirworld.com
www.cirworld.com, member.cirworld.com 


\section{Introduction}

Pollution of water (ground, surface...etc) with metals (and especially heavy metals) increased rapidly during the last years. Human activities have increased the concentrations of heavy metals in the environment. For example, anthropogenic activities e.g. industry, agriculture, solid waste disposal increase the contents of heavy metals in different environmental matrices (e.g. water, soil, air), fruits, vegetables, fish..etc (Batayneh 2010; Abderahman and Abu-Rukah 2006; Adekunle et. al. 2007; Chen et. al. 2007).

Heavy metals are widespread pollutants of great environmental concern as they are nondegradable, toxic, and persistent (5). Heavy metals and some trace elements are biologically toxic and can affect and threaten the health of human being owing to their accumulation and persistence in the compartments of the food chain. There are 35 metals that concern us because of occupational or residential exposure; 23 of these are heavy metals: antimony, arsenic, bismuth, cadmium, cerium, chromium, cobalt, copper, gallium, gold, iron, lead, manganese, mercury, nickel, platinum, silver, tellurium, thallium, tin, uranium, vanadium, and zinc (Ferner 2001). Small amounts of these elements are common in our environment and diet, and some are necessary for good health, but large amounts of any of them may cause acute or chronic toxicity. Health risks of heavy metals include reduced growth and development, cancer, organ damage, nervous system damage, and in extreme cases, death. Exposure to some metals, such as mercury and lead, may also cause development of autoimmunity, in which a person's immune system attacks its own cells. Heavy metals become toxic when they are not metabolized by the body and accumulate in the soft tissues. Heavy metals may enter the human body via food, water, air, or absorption through the skin in agriculture, industrial, or residential settings (Roberts 1999; Dupler 2001).

There is an increasing need to determine concentrations of heavy metals simultaneously, rapidly, accurately, precisely, and at low concentrations (low limit of quantitation LOQ). Inductively coupled plasma mass spectrometry, ICP-MS, has become to be one of the most attractive detection systems and is routinely used in many diverse research fields such as earth, environmental, life and forensic sciences and in food, material, chemical and nuclear industries [9]. Inductively coupled plasma-mass spectrometry (ICP-MS) is powerful technique for trace analysis of elements and it is preferred for ultratrace levels due to its higher sensitivity [10-12]. ICP-MS is a multi-element technique for analyzing liquid samples, characterized by high selectivity, sensitivity and detection limits much lower than other multi-element techniques.

The purpose of this paper is to validate a method for determination of different trace metals in water by inductively coupled plasma mass spectrometry (ICP-MS) method which are usually detected in polluted water. Validation of the method will be conducted in accordance with requirements of new methods which include linearity and range, accuracy, precision, selectivity, limit of detection, and limit of quantitation. According to our best knowledge, this study is not conducted before.

\section{Experimental}

\subsection{Chemicals}

Ultrapure nitric acid, multi-standard containing 22 metals (Ag 10 ppm, Al 50 ppm, B 50 ppm, Ba 10 ppm, Bi 100 ppm, Ca 10 ppm, Cd 10 ppm, Co 10 ppm, Cr 50 ppm, Cu 10 ppm, Fe 10 ppm, K 100 ppm, Li 50 ppm, Mg 10 ppm, Mn 10 ppm, Mo 50 ppm, Na 50 ppm, Ni 50 ppm, Pb 100 ppm, Sr 10 ppm, TI 50 ppm, Zn 10 ppm, matrix 5\% $\mathrm{HNO}_{3}$ ) are from Merck (Darmstadt, Germany). Ultra-pure de-ionized water $\left(18 \mathrm{M} \Omega \mathrm{cm}^{-1}\right)$ from a Milli-Q analytical reagent grade water purification system (Millipore) was used.

\subsection{ICP/MS instrument}

The Agilent Technologies 7500 Series ICP-MS (Agilent 7500) can measure trace elements as low as one part per trillion (ppt) and quickly scan more than 70 elements to determine the composition of an unknown sample with a MassHunter Workstation software automates the analysis and accurately interprets the resulting data. The ICP/MS instrument consists of an on- board peristaltic pump that controls the flow of sample solution into and waste (drain) out of the instrument, a nebulizer (Micro Mist nebulizer) that uses a stream of argon to disperse the sample, an ICP Argon plasma torch using Argon as plasma gas, auxillary gas and nebulizer (carrier) gas, two pumps for evacuation, quadrupole mass analyzer with 0.8 amu resolution at $10 \%$ height, an octapole reaction system (ORS), and electron multiplier detector.

\subsection{Method of analysis}

For accurate quantitative determination of trace metals in water samples, an internal standard method was used using $Y$ as internal standard and a multi-standard calibration method. The operating conditions of the ICP/MS method are as follows: nebulizer gas (argon) flow rate: $0.9 \mathrm{~L} / \mathrm{min}$, auxiliary gas (argon) flow $0.3 \mathrm{~L} / \mathrm{min}$, plasma (Argon) gas flow: $15 \mathrm{~L} / \mathrm{min}$, reaction gas flow (helium) $4 \mathrm{~mL} / \mathrm{min}$, lens voltage $7.25 \mathrm{~V}$, ICP RF power: $1100 \mathrm{~W}, \mathrm{CeO} / \mathrm{Ce}=1 \%$, and $\mathrm{Ce}^{+2} / \mathrm{Ce}^{+1}=1 \%$.

\subsection{Preparation of solutions}

Six solutions of the seventeen metals with concentrations: 1.0, 5.0,100.0, 300.0, 500.0, and 1000.0 ppb were prepared from the stock multi-standard by dilution using $0.5 \%$ ultrapure nitric acid as diluent. These solutions were used for linearity and range study of the method. For recovery of the studied metals from water, three concentrations of the metals (1.0, 100.0 , and $1000.0 \mathrm{ppb}$ ) were prepared by spiking of the metals in Milli-Q water that does not contain trace metals to get three spiked concentrations of each metal (1.0, 100.0, and $1000.0 \mathrm{ppb})$. Each sample was analyzed three times and the results are expressed as mean \pm SD (SD: standard deviation). The solutions which prepared for linearity with 
concentrations of $1.0,100.0$, and $1000.0 \mathrm{ppb}$ were used for precision study. To determine LOD and LOQ of the method, the solution with $5 \mathrm{ppb}$ which is prepared for linearity study was used.

\section{Results and discussion}

Validation of new methods for determination of different analytes in a matrix or sample requires different parameters: linearity and range, accuracy, precision (repeatability, and intermediate precision), selectivity, limit of detection, and limit of quantitation.

\subsection{Method validation}

\subsubsection{Linearity and range}

Linearity is the ability of a method to elicit test results that are directly proportional to analyte concentration within a given range. Linearity is generally reported as the variance of the slope of the regression line. Range is the interval between the upper and lower levels of the analyte that have been demonstrated to be determined with precision, accuracy, and linearity using the method to be developed. The range is normally expressed in the same units as the results obtained by the method. A minimum of five concentration levels along with certain minimum specified ranges are required. Acceptance criteria for linearity are that the correlation coefficient $\left(R^{2}\right)$ is not less than 0.990 for the least squares method of analysis of the line (13).

To evaluate linearity of the method, six calibration standards of the metals with concentrations of $1,5,100,300,500$, and $1000 \mathrm{ppb}$ were analyzed by ICP-MS and the responses are recorded. A plot of the ratio of response (cps) of the metal analyte divided by the response of the internal standard $(Y)$ versus concentration of the metal (in ppb) was found to be linear in the range of $1-1000 \mathrm{ppb}$, and with a correlation coefficient of better than 0.999 for the metals analyzed in this study. This result demonstrates linearity of this method over the specified range.

\subsubsection{Accuracy (percentage recovery)}

The accuracy of an analytical method measures the closeness of the agreement between the value, which is accepted either as a conventional true value or an accepted reference value, and value found (i.e., accuracy is a measure of exactness of an analytical method). Accuracy is measured as the percent of analyte recovered by assay after spiking samples in a blank. To document accuracy, a minimum of nine determinations over a minimum of three concentration levels covering the specified range (for example, three concentrations, three replicates for each) were collected. It is performed at three concentrations covering the range of the method. At each level studied, replicate samples are evaluated. The RSD of the replicates provides the analysis variation and gives an indication of the precision of the test method. Moreover, the mean of the replicates, expressed as \% of label claim, indicates the accuracy of the test method. The mean recovery of the assay should be within $100 \pm 5.0 \%$ at each concentration over the studied range (14).

To evaluate accuracy of the method, three spiked solutions of the metals with three concentrations $(1.0,100.0$, and 1000.0) are prepared by spiking specific volume of the metals stocks solution into a blank (Mili-Q water which is highly pure (conductivity $=18 \mathrm{M} \Omega \mathrm{cm}^{-1}$ ) and does not contain the studied trace metals). These solutions, then, have been analyzed by the current method. Three runs have been performed for every concentration, and then responses (cps) have been recorded. The percentage recovery of the metals in water was calculated by proportion of the concentration of the element found in the spiked recovery solution (which is obtained from the calibration curve) to the theoretical concentration of that metal. The average recovery and the RSD for each level have been calculated. Results have shown that the \% recovery of the metals from water at the three concentration levels $(1.0,100.0$, and $1000.0 \mathrm{ppb})$ ranged from $97.5 \%$ to $101.7 \%$, and with a relative standard deviation lower than $1.0 \%$, see Table 1.

Table 1: \% Recovery of the metals analyzed in this study from water at three concentration levels.

\begin{tabular}{|c|c|c|c|}
\hline \multirow{3}{*}{ Metal } & \multicolumn{3}{|c|}{$\%$ recovery } \\
\hline & \multicolumn{3}{|c|}{ Concentration (ppb) } \\
\hline & 1.0 & 100.0 & 1000.0 \\
\hline \multirow{4}{*}{$\mathrm{Li}$} & $99.0,99.6,100.2$ & $97.9,98.2,99.1$ & $100.1,101.2,99.6$ \\
\hline & Mean: 99.6 & Mean: 98.4 & Mean: 100.3 \\
\hline & $S D^{*}: 0.6$ & SD: 0.62 & SD: 0.82 \\
\hline & $\mathrm{RSD}^{* *}: 0.60 \%$ & RSD: $0.63 \%$ & RSD: $0.82 \%$ \\
\hline \multirow{4}{*}{$\mathrm{Sr}$} & $101.0,100.8,101.1$ & $100.3,99.7,99.1$ & $100.9,101.0,100.8$ \\
\hline & Mean: 101.0 & Mean: 99.7 & Mean: 100.9 \\
\hline & SD: 0.15 & SD: 0.60 & SD: 0.10 \\
\hline & RSD: 0.15 & RSD: $0.60 \%$ & RSD: $0.10 \%$ \\
\hline $\mathrm{Ba}$ & $99.3,98.1,97.6$ & $98.7,97.8,99.1$ & $101.0,100.7,100.9$ \\
\hline
\end{tabular}




\begin{tabular}{|c|c|c|c|}
\hline & Mean: 98.3 & Mean: 98.5 & Mean: 100.9 \\
\hline & SD: 0.87 & SD: 0.67 & SD: 0.15 \\
\hline & RSD: 0.88 & RSD: $0.68 \%$ & RSD: 0.15 \\
\hline \multirow{4}{*}{$\mathrm{TI}$} & $97.1,98.1,100.2$ & $99.1,100.0,100.5$ & $98.2,99.5,100.0$ \\
\hline & Mean: 98.5 & Mean: 99.9 & Mean: 99.2 \\
\hline & SD: 1.58 & SD: 0.71 & SD: 0.93 \\
\hline & RSD: 1.60 & RSD: $0.71 \%$ & RSD: $0.94 \%$ \\
\hline \multirow{4}{*}{$\mathrm{Pb}$} & $101.0,101.5,100.8$ & $100.2,100.9,101.0$ & $101.3,100.2,99.8$ \\
\hline & Mean: 101.1 & Mean: 100.7 & Mean: 100.4 \\
\hline & SD: 0.36 & SD: 0.43 & SD: 0.77 \\
\hline & RSD: $0.36 \%$ & RSD: 0.43 & RSD: $0.77 \%$ \\
\hline \multirow{4}{*}{$\mathrm{Bi}$} & $98.1,99.6,100.0$ & $98.9,97.9,97.6$ & $99.6,99.8,99.1$ \\
\hline & Mean: 99.2 & Mean: 98.1 & Mean: 99.5 \\
\hline & SD: 1.0 & SD: 0.68 & SD: 0.36 \\
\hline & RSD: $1.0 \%$ & RSD: 0.69 & RSD: $0.36 \%$ \\
\hline \multirow{4}{*}{ Al } & $99.2,100.5,98.9$ & $100.8,101.0,100.1$ & $100.5,100.0,99.8$ \\
\hline & Mean: 99.5 & Mean: 100.6 & Mean: 100.1 \\
\hline & SD: 0.85 & SD: 0.47 & SD: 0.36 \\
\hline & RSD: $0.85 \%$ & RSD: 0.47 & RSD: $0.36 \%$ \\
\hline \multirow{4}{*}{ K } & $98.1,99.6,100.0$ & $100.5,99.8,100.0$ & $101.1,100.8,100.1$ \\
\hline & Mean: 99.2 & Mean: 100.1 & Mean: 100.7 \\
\hline & SD: 1.0 & SD: 0.36 & SD: 0.51 \\
\hline & RSD: $1.0 \%$ & RSD: $0.36 \%$ & RSD: $0.51 \%$ \\
\hline \multirow{4}{*}{$\mathrm{Cr}$} & $98.1,99.2,98.8$ & $99.6,100.1,99.9$ & $97.6,98.5,98.0$ \\
\hline & Mean: 98.7 & Mean: 99.9 & Mean: 98.0 \\
\hline & SD: 0.55 & SD: 0.25 & SD: 0.45 \\
\hline & RSD: $0.56 \%$ & RSD: $0.25 \%$ & RSD: 0.46 \\
\hline \multirow{4}{*}{$\mathrm{Mn}$} & $101.0,100.5,100.4$ & $100.5,99.9,100.2$ & $101.2,100.4,99.8$ \\
\hline & Mean: 100.6 & Mean: 100.2 & Mean: 100.5 \\
\hline & SD: 0.32 & SD: 0.30 & SD: 0.70 \\
\hline & RSD: $0.32 \%$ & RSD: $0.30 \%$ & RSD: $0.70 \%$ \\
\hline \multirow{4}{*}{ Co } & $100.5,101.1,99.6$ & $99.6,101.0,100.1$ & $99.9,100.5,99.1$ \\
\hline & Mean: 100.4 & Mean: $100.2 \%$ & Mean: 99.8 \\
\hline & SD: 0.75 & SD: 0.71 & SD: 0.70 \\
\hline & RSD: $0.75 \%$ & RSD: $0.71 \%$ & RSD: $0.70 \%$ \\
\hline \multirow{4}{*}{$\mathrm{Ni}$} & $101.1,101.0,100.4$ & $101.5,100.5,100.7$ & $99.8,99.1,100.5$ \\
\hline & Mean: 100.8 & Mean: 100.9 & Mean: 99.8 \\
\hline & SD: 0.38 & SD: 0.53 & SD: 0.70 \\
\hline & RSD: $0.38 \%$ & RSD: $0.52 \%$ & RSD: $0.70 \%$ \\
\hline \multirow{3}{*}{$\mathrm{Cu}$} & $99.2,100.2,98.6$ & $99.8,97.8,99.1$ & $100.1,100.9,99.6$ \\
\hline & Mean: 99.3 & Mean: 98.9 & Mean: 100.2 \\
\hline & SD: 0.81 & SD: 1.01 & SD: 0.66 \\
\hline
\end{tabular}




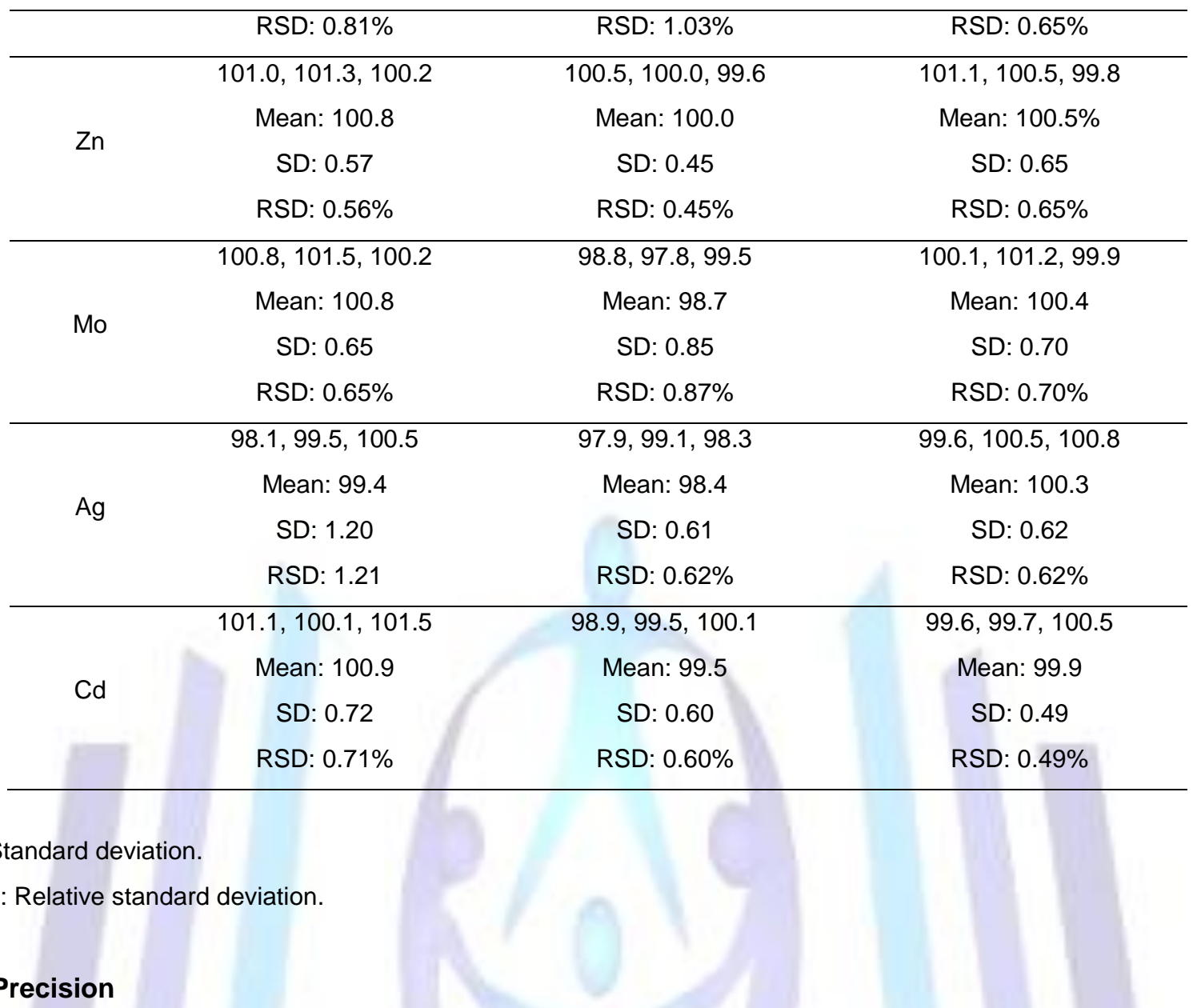

Precision is the measure of the degree of repeatability of an analytical method under normal operation and is normally expressed as the RSD for a statistically significant number of samples. There are two types of precision: repeatability and intermediate precision (ruggedness).

\subsubsection{Repeatability}

Repeatability is the closeness of agreement between mutually independent test results obtained with the same method on identical test material in the same laboratory by the same operator using the same equipment within short intervals of time. It is determined from a minimum of nine determinations covering the specified range of the procedure (for example, three levels, three repetitions each). RSD for replicate injections should not be greater than $1.5 \%$ (15).

Repeatability of the current method for determination of the seventeen metals was evaluated by calculating the RSD of the responses (in cps) of six replicate injections of standard solutions of the seventeen metals with three concentrations (1.0, 100 , and $1000.0 \mathrm{ppb}$ ), which was found to be less than $1.5 \%$ for all metals at the three concentration levels (data not shown). These results show that the current method for determination of the metals is repeatable.

\subsubsection{Intermediate precision (Ruggedness)}

Intermediate precision (also called ruggedness) of a method measures the repeatability of the result obtained with the same method, on the same sample, in the same laboratory, but by different operators and in different day. Intermediate precision of the current method for trace metals determination was evaluated by calculating the \% recovery of the metals at three concentration levels $(1.0,100.0$, and $1000.0 \mathrm{ppb})$ prepared by another analyst in a different day using the same ICP-MS instrument. Results of this study showed that the \% recovery obtained is very close to that obtained by the main analyst and ranges from 98.2 to $101.8 \%$ (data not shown), indicating that this method is rugged.

\subsubsection{Selectivity}

Selectivity is the ability to assess unequivocally the analyte in the presence of other analytes and other components that may be expected to be present in the matrix or sample (16). It is a measure of the degree of interferences from such components, ensuring that a response is due to a single component only. Selectivity of the current method was demonstrated by good separation of the metals peaks (responses) with low interferences. The resolution of adjacent metal peaks from each other is $0.8 \mathrm{amu}$ at $10 \%$ height. Furthermore interferences from oxides and doubly charged is low $\left(\mathrm{CeO} / \mathrm{Ce}\right.$, and $\mathrm{Ce}^{+2} / \mathrm{Ce}^{+1}$ is $\left.1 \%\right)$. 


\subsubsection{Limit of detection (LOD)}

LOD is the lowest concentration of analyte in a sample which can be detected but not necessarily quantitated under the stated experimental conditions. To determine the limit of detection, blank (ultra pure water of $18.2 \mathrm{M} \Omega \mathrm{cm}^{-1}$ ) was aspired and signal intensities for the blank were recorded. Then, a solution of $5.0 \mathrm{ppb}$ of all studied metals was aspired and the signal intensities for these analytes were recorded. The limit of detection was calculated by the following equation (5).

$$
\mathrm{LOD}=3 \cdot \mathrm{SD}_{\text {blank }} \cdot \text { conc }_{\text {sample }} /\left(I_{\text {sample }}-I_{\text {blank }}\right)
$$

where: SDblank is the standard deviation for the signal recorded on the blank for the

metal studied; concsample is the concentration [ppb] of the analyte in the sample, Isample, Iblank are the signal intensities recorded for the sample and blank respectively. Table 2 shows the LOD of the metals analyzed in this study.

Table 2: LOD and LOQ of the seventeen metals determined by the current ICP-MS method.

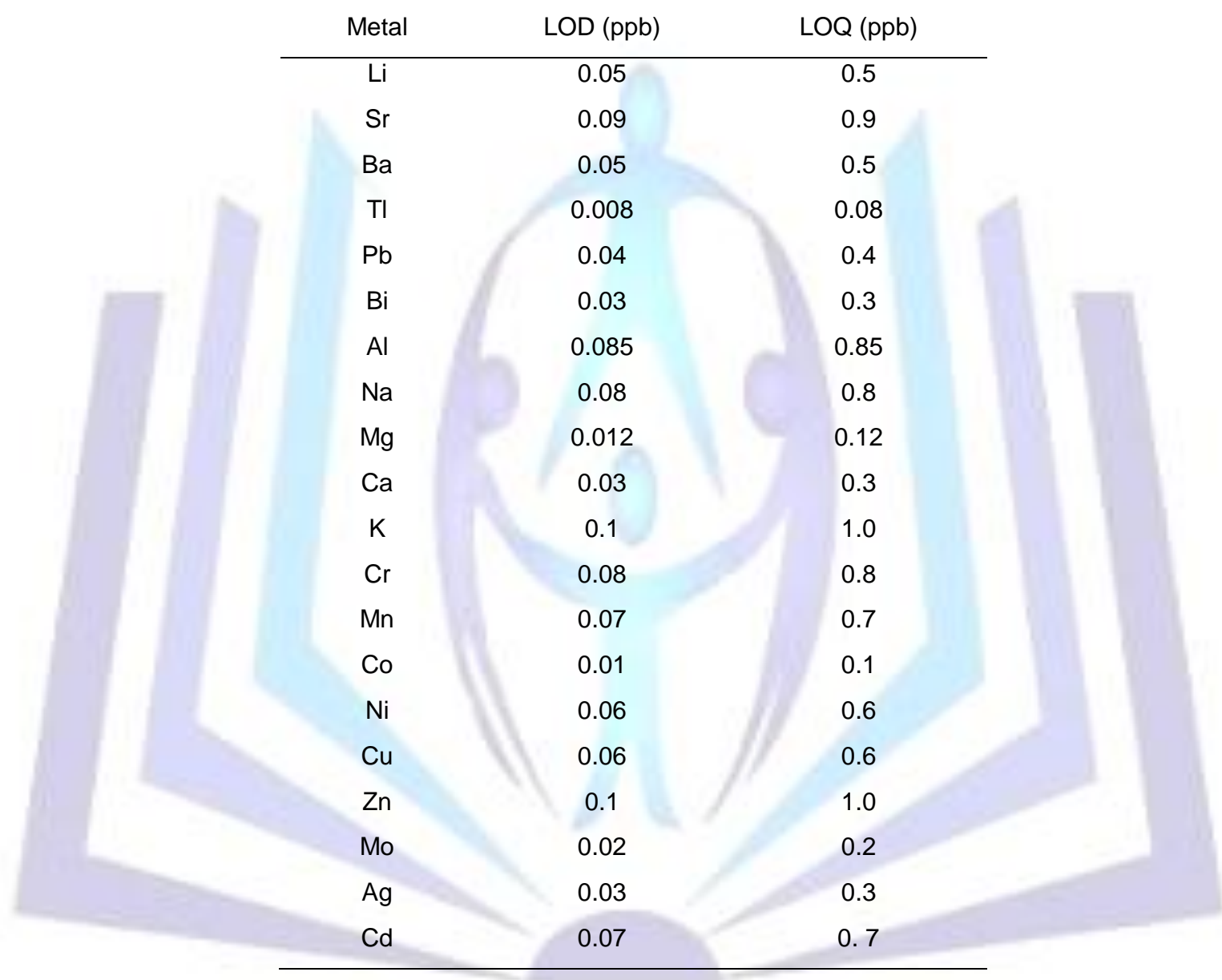

\subsubsection{Limit of quantitation (LOQ)}

$\mathrm{LOQ}$ is the lowest concentration that can be quantitatively determined with an acceptable level of repeatability and accuracy. The LOQ is generally considered to be approximately ten times the LOQ (Table 2). As we can see from table 2 , low LOD and LOQ of the seventeen metals are obtained, which permits the determination of theses metals in water at low concentrations.

\subsection{Application of the method to real water samples}

After successful development and validation of this method for simultaneous determination of the seventeen metals, it was employed for analysis of these metals in groundwater of West Bank/Palestine to assess the quality of this groundwater which is used for drinking in West Bank. Water samples from ten groundwater wells were obtained in four different dates of the year (October 2012, November 2012, March 2013, and April 2013). Three water samples were obtained from each well for each sampling date. A total of 120 water samples were collected from the ten wells. Results showed that $\mathrm{TI}$, $\mathrm{Pb}$, $\mathrm{Bi}, \mathrm{Cr}, \mathrm{Mn}, \mathrm{Co}, \mathrm{Ni}, \mathrm{Cu}, \mathrm{Zn}, \mathrm{Mo}, \mathrm{Ag}$, and $\mathrm{Cd}$, and $\mathrm{Al}$ were detected in one or more of the wells investigated. It was found that $\mathrm{Pb}, \mathrm{Al}, \mathrm{Cr}, \mathrm{Co}, \mathrm{Ni}, \mathrm{Cu}, \mathrm{Zn}$, and $\mathrm{Mo}$ were detected in all water samples, while $\mathrm{Tl}, \mathrm{Bi}, \mathrm{Mn}, \mathrm{Ag}$, and $\mathrm{Cd}$ were detected in $80 \%, 88 \%, 90 \%, 75 \%$, and $95 \%$ of the water samples analyzed in this study, respectively. In general, $93 \%$ of all samples 
analyzed contained one or more of the 13 metals studied each in varying concentration. Furthermore, results showed that the concentration of $\mathrm{Cr}, \mathrm{Mn}, \mathrm{Ni}, \mathrm{Cu}, \mathrm{Zn}$, and $\mathrm{Mo}$ is within the allowed WHO limits in drinking water. However the concentration of $\mathrm{Pb} \mathrm{Cd}$, and $\mathrm{Al}$ are found to be higher than the allowed WHO limits in $40 \%, 8 \%$, and $33 \%$ of the water samples analyzed, respectively. It is concluded that this ICP-MS method can be used for quantitative simultaneous determination of these metals in groundwater.

\section{Conclusions}

A simple, accurate, precise, and selective ICP-MS method was validated for the simultaneous determination of seventeen metals in water. The method is linear for the determination of these metals in the range of $1.0-1000.0$ ppb. This method is also accurate where the \% recovery of the metals is within $97.5-101.7 \%$. Precision of the method is confirmed by low RSD of replicate samples of the metals. Low LOD and LOQ of the metals analyzed in this study enable the detection and quantitation of them in water at low concentrations. This validated method can be employed for the determination of these metals in real water samples (ground, surface, wastewater..etc).

\section{REFERENCES}

[1] Abderahman, N., and Abu-Rukah Y. 2006. An Assessment Study of Heavy Metal Distribution within Soil in Upper Course of Zarqa River Basin/Jordan. Environ. Geol. 49, 1116-1124.

[2] Adekunle, I., Adetunji, M., Gbadebo A. and Banjoko, O. 2007. Assessment of Groundwater Quality in a Typical Rural Settlement in Southwest Nigeria. Public Health Int. J. Environ. Res., 4, 307-318.

[3] Chen, C., Kao, C., Chen, C., and Dong, C. 2007. Distribution and Accumulation of Heavy Metals in the Sediments of Kaohsiung Harbor, Taiwan. Chemosphere, 66, 1431-1440.

[4] Batayneh, A. T. 2010. Heavy metals in water springs of the Yarmouk Basin, North Jordan and their potentiality in health risk Assessment. International Journal of the Physical Sciences. 5(7), 997-1003.

[5] Voica, C., Dehelean, A., Iordache A., Geana, I., 2012. Method validation for determination of metals in soils by ICP-MS, Romanian Reports in Physics, 64 (1), 221-231.

[6] Ferner, D.J. 2001. Toxicity and Heavy metals. eMedicine Journal, 2 (5),1.

[7] Roberts, H. 1999. Lead poisoning (Accessed 01-02-09). Available online at http://www.setlet.com.

[8]. Dupler, D. 2001. Heavy metal poisoning. Gale Encyclopedia of Alternative medicine. Farmington Hills, Gale group. 2054-2057.

[9] Adrian, A. Ammann. 2007. Inductively coupled plasma mass spectrometry (ICP-MS): a versatile tool, J.Mass Spectrom., 42, 419-427.

[10] Yang X. J., C. Low G. K. 2009. Validation of a digestion procedure for ICP-AES and dynamic reaction cell ICP-MS for trace elemental analysis in environmental samples. Environ Chem Lett., 7, 381-387.

[11] N. Gilon, Can. 2005. J. Anal. Sci. Spectrosc., 50, 5, 240-254.

[12] Hoffman, E., Ludke, C. , and Scholze, H. 1997. Is laser-ablation-ICP-MS and alternative to solution analysis of solid samples? Fressenius J. Anal. Chem., 359, 394-398.

[13] International Conference on Harmonization (ICH), "Validation of Analytical Procedures-PA/PH/OMCL (05) 47 DEF", elaborated by OMCL Network/EDQM of the Council of Europe, June 2005.

[14] Green, M. 1996. a Practical Guide to Analytical Method Validation; Analytical Chemistry News and Features, P. 309A.

[15] Huber, L. 1998. Validation of Analytical Methods, in "Validation and Qualification in the Analytical Laboratories", Interpharm Press, Buffalo Grove, IL, 107.

[16] A WHO Guide to Good Manufacturing Practice (GMP) Requirements, Part 2: Validation,World Health Organization, Geneva, 1997. 